\title{
INDICADORES DE CONSUMO CONSCIENTE: uma avaliação do recifense sob a ótica do consumo sustentável
}

\section{1- Minelle Enéas da Silva}

Doutorando em Administração pela Universidade Federal do Rio Grande do Sul (UFRGS), Brasil. minele.adm@gmail.com

http://lattes.cnpq.br/3329329091837689

\section{2- Alice Paz Marques de Oliveira}

Graduanda em Administração pela Universidade Federal de Pernambuco (UFPE), Brasil. alicepmarques@gmail.com

http://lattes.cnpq.br/1204231206202214

\section{3- Carla Regina Pasa Gómez}

Professora do Programa de Pós-Graduação em Administração da Universidade Federal de Pernambuco (PROPAD/UFPE), Brasil.

carlapasagomez@gmail.com

http://lattes.cnpq.br/1964176230213353

\author{
Diego Maganhotto Coraiola - Editor Geral \\ Editor responsável pela submissão: \\ Diego Maganhotto Coraiola. \\ Artigo analisado via processo de revisão duplo cego (Double-blind). \\ Recebido em: 06/12/2012 \\ Aprovado em: 24/03/2013 \\ Última Alteração: 24/03/2013
}

* Contato Principal: Rua General Lima e Silva, 30 - Apto 402 - Centro. Porto Alegre - RS - Brasil. CEP: 90.050-100. 

INDICADORES DE CONSUMO CONSCIENTE: UMA AVALIAÇÃO DO RECIFENSE SOB A ÓTICA DO
CONSUMO SUSTENTÁVEL

\section{RESUMO}

Diante das modificações socioambientais observadas, mudanças nos comportamentos têm demonstrado uma nova perspectiva de atuação tanto individual quanto coletiva. Assim sendo, focando na atuação do indivíduo enquanto consumidor, o presente artigo tem por objetivo articular um conjunto de indicadores de consumo consciente para a identificação do comportamento da população de Recife/PE, sob a perspectiva do consumo sustentável. Com abordagem quantitativa, realizou-se uma pesquisa do tipo survey com 601 recifenses a partir dos 40 indicadores de consumo consciente identificados na literatura. Como apresenta os resultados, existe um direcionamento considerado 'suave' para uma prática consciente de consumo, entendendo serem necessárias interações com outros atores sociais. Além disso, se observa com a realização dos testes que a variável escolaridade apresenta maior influência sobre o comportamento, pela grande quantidade de diferença de médias. Com isso, o conjunto de indicadores agrupados para a realização dessa pesquisa a partir do Greendex, do Instituto Akatu e do Ecological Footprint Method, apresenta uma contribuição positiva para o estudo do consumo consciente de uma população sob a perspectiva do consumo sustentável.

Palavras-chave: Consumo sustentável; Consumo consciente; Indicadores.

\section{CONSCIOUS CONSUMPTION INDICATORS: AN EVALUATION OF RECIFE (BRAZIL) INHABITANT FROM SUSTAINABLE CONSUMPTION APPROACH}

\section{ABSTRACT}

From the current environmental and social changes, the new behaviors had show a different view for individual and collective actions. Thus with the focus in individuals as consumers, this paper aims to articulate a set of conscious consumption indicators to identify the behaviors of Recife (Brazil) inhabitants from the sustainable consumption perspective. We used a quantitative approach through a survey with 601 individuals living in this city, adopting 40 indicators identified in academic literature. The main result had shown a little involvement of this population with conscious consumer practices, in which it is necessary to have the new interaction with the social actors. In addition, we identified according to the tests that the item schooling has a big influence on the behaviors from the great amount of difference in averages. Therefore, the set of indicators identified for this research from tools Greendex, Instituto Akatu and Ecological Footprint Method shown a positive contribution for conscious consumption studies in relation to sustainable consumption approach.

Keywords: Sustainable consumption; Conscious consumption; Indicators. 


\section{Introdução}

Cada vez mais se percebe que a atual prática de consumo pode ser considerada como uma barreira ao alcance da sustentabilidade, isso ocorre pelo consumismo vivenciado e pelas características inerentes a sociedade de consumo a qual se está inserido (Assadourian, 2010). Apesar da atribuição constante às empresas quanto à "culpa" pela insustentabilidade, pelos bens e serviços que são ofertados, as práticas de consumo individuais também possuem um papel de responsabilidade nesse contexto. Isso ocorre não apenas aos indivíduos, mas também a um conjunto de outros atores, que geram cada vez mais impactos socioambientais negativos. Como indicam De Toni, Mattia, Larentis e Silva (2010), o ato de consumir é algo individual e coletivo, e está envolto por um conjunto de significados e valores sociais.

Numa perspectiva mais crítica, para a construção de um ideal, Foladori (2005) atribui ao consumo, em paralelo à pobreza, as principais causas da distância entre a teoria e a prática na busca por um Desenvolvimento Sustentável. De forma semelhante, Lenzen, Murray, Sack e Wiedmann (2007) corroboram com o pensamento ao indicar que o consumo final e o padrão de consumo de economias emergentes são os principais geradores dos problemas ambientais. Todavia, os impactos que são identificados não apenas envolvem as considerações dos autores, pois as maiores taxas de consumo, pela quantidade monetária e aspectos culturais existentes, envolvem principalmente os países mais desenvolvidos, mesmo que ainda estejam inseridos em um contexto de crise econômica.

Tais discussões se direcionam a identificar quem são os responsáveis pelo problema, sem muito contribuir com alternativas para saná-lo. Diante dessa visão, entende-se que no processo de definição dos papéis que devem ser adotados para o alcance da sustentabilidade, surge às discussões inerentes ao estudo das relações que permeiam essa ideia, dentre as quais as relações de consumo. Desse modo, sabe-se que para uma mudança coletiva do modelo emergente de desenvolvimento, o estudo do consumo sustentável se faz necessário pelo conjunto de interações sociais que é exigido (Michaelis, 2003). Tal padrão de consumo deve ser estudado para se compreender quais são os principais aspectos diretos e indiretos inerentes ao desenvolvimento sustentável (Jackson, 2007).

Assim, focando a perspectiva individual nesse contexto de mudança, o conceito de consumo consciente surge como um dos principais meios para se mudar o perfil de consumo individual (Seyfang, 2006), isso envolve a escolha de produtos ambientalmente corretos com menor impacto ambiental no pós-consumo ou de produtos de empresas socialmente justas. Nessa linha de pensamento, Dobson (2003) propõe o desenvolvimento do conceito de cidadão ecológico, como um consumidor sensível à responsabilidade social e ambiental em escala planetária e não apenas individual. Este cidadão exerce tal comportamento diariamente no intuito de reduzir os seus impactos negativos (e os de outros consumidores), incorporando essa atitude na sua tomada de decisão e na formação do seu comportamento de compra.

Surge desse modo um movimento na sociedade para um consumo mais responsável, o qual considera que essa prática estimula um novo ator, o consumidor-cidadão (Portilho, 2005; Santos, Leite, Tacconi \& Alexandre, 2008; Seyfang, 2006; Spaargaren \& Oosterveer, 2010). Numa perspectiva prática, no sentido de reconhecer características e desenvolver alternativas para o contexto ao qual se vive (tanto para empresas como para consumidores) para a adoção de um comportamento pró-ativo em relação à sustentabilidade, faz-se necessário utilizar instrumentos de avaliação do consumo de modo tal que seja facilitada a atuação de diferentes atores por um padrão sustentável de consumo.

Em meio a essa perspectiva, deve-se considerar a existência de diferentes formas de consumo para assim buscar melhores resultados. A partir de uma revisão teórica exploratória, foram identificados alguns instrumentos de análise da prática de consumo de diferentes populações, num contexto local, regional ou nacional, cujos resultados permitem visualizar a efetividade das iniciativas e alternativas capazes de promover uma mudança individual e coletiva. Todavia, como se verificou existe grande confusão quanto às variações de consumo que podem ser verificadas, o que abre uma lacuna para o desenvolvimento de pesquisas.

A partir dessa ideia, o objetivo deste artigo é articular um conjunto de indicadores de consumo consciente para a identificação do comportamento da população de Recife - PE, sob a ótica do consumo sustentável. Sua realização está justificada na necessidade de buscar sanar a lacuna teórica existente sobre mensuração, buscando alinhar diferentes tipos de indicadores direcionados a uma mesma perspectiva de consumo. É nesse ponto que se encontra a maior contribuição da presente pesquisa que conhecendo os comportamentos podemse criar soluções mais efetivas, por empresas ou governos. Para tanto, foram desenvolvidas duas etapas, uma inicial com a articulação dos indicadores analisados buscando criar um conjunto homogêneo e, a segunda, com a aplicação desses indicadores à população selecionada.

Com as análises foram identificados resultados importantes para as discussões sobre a temática, uma vez que as variáveis 'renda familiar' e 'escolaridade' trazem a possibilidade de maiores inferências e criam alternativas para futuras pesquisas. Para melhor compreender o objetivo proposto, o presente artigo está dividido em quatro partes além dessa introdutória. Em seguida são observados os aspectos teóricos norteadores da pesquisa, o qual mostra a diferença clara existente entre as tipologias de consumo, bem como com a articulação dos indicadores utilizados na pesquisa. Noutro momento os procedimentos metodológicos, a apresentação e análise dos resultados, e, por fim, as considerações finais, contemplando a contribuição teóricoempírica da pesquisa para as discussões acadêmicas. 


\section{Discussão Teórica}

As discussões sobre o desenvolvimento sustentável buscam apresentar a necessidade de equilíbrio na interação entre os seres humanos e a natureza. Embora o desafio de se atingir a sustentabilidade de uma localidade seja considerado como utópico, o mesmo possui como definição mais disseminada àquela apresentada no Relatório de Brundtland, no qual é entendido como "um processo de mudança em que a exploração dos recursos, a direção dos investimentos, a orientação do desenvolvimento tecnológico e a mudança institucional estão todos em harmonia" para que as necessidades humanas possam ser satisfeitas atualmente e no futuro (World Comission on Environment and Development [ WCDE], 1987, n.p.).

Para tanto, entende-se como necessária a busca pela harmonia entre as dimensões básicas do desenvolvimento sustentável, quais sejam: a econômica, a social e a ambiental (Sachs, 2007; VanBellen, 2005), de modo que se torne possível a prática de diferentes papéis sociais por vários atores na sociedade. Com isso, percebe-se que essas dimensões englobam a facilidade em resolver problemas causados por uma falta de equilíbrio no desenvolvimento, a capacidade de gerar excedentes e o respeito à obrigação de preservar a base ecológica do desenvolvimento (WCDE, 1987). Isso se torna facilitado com a realização de um conjunto de interações entre atores, com o indivíduo responsável pelas decisões que são tomadas.

Desse modo, considera-se que deve haver um aumento na preocupação coletiva em relação a uma prática individual em relação ao desenvolvimento, considerando as interações constantes que ocorrem. Segundo Silva (2012), à medida que o pensamento individualista, resultante do modelo capitalista, for reestruturado, ter-se-á uma aproximação ao alcance do desenvolvimento sustentável. Tal fato indica que ações precisam ser desenvolvidas, a partir de uma busca conjunta e articulada entre os governos, as empresas e o indivíduo, enquanto atores que devem mudar suas relações e melhorar o padrão de consumo na sociedade. A partir disso discute-se o conceito de consumo sustentável.

\subsection{Consumo Sustentável: Um Padrão que Engloba o Consumo Consciente}

A prática do consumo acompanha o ser humano em todos os momentos de sua existência, direta ou indiretamente, o que ratifica a ideia de que não é possível o viver sem consumir (Silva, 2012). Como apresentado pelo Instituto Akatu (2001), o ato de consumir é um processo que, geralmente, é realizado de forma automática e, muitas vezes, de forma impulsiva, devendo-se entender que o mesmo está relacionado com a decisão sobre o que, o porquê, o como e de quem consumir, além da efetivação da compra e o pósconsumo, no momento que é necessário descartar o que foi utilizado. Esse processo pode ser observado de forma singular quanto aos bens materiais e serviços prestados, podendo estar relacionado a sentimentos como o bem-estar e satisfação momentânea.

Em uma perspectiva mais efetiva com relação à atuação do consumidor na sua prática de consumo identificam-se forças contextuais que interferem diretamente no comportamento desse indivíduo, dentre as quais, para Michaelis (2000): (1) tendências humanas intrínsecas - consumismo; (2) crescimento tecnológico e institucional; (3) consumismo material; (4) sistema de mercado competitivo; e (5) busca pela qualidade de vida. Tais aspectos indicam um conjunto de modificações que devem ser observadas, tanto na atuação dos indivíduos em suas escolhas, como de outros atores que por meio de novos comportamentos conseguem facilitar a reestruturação da prática atual.

Assim, tem-se o conceito de consumo sustentável que envolve o surgimento de uma nova perspectiva em relação às estratégias públicas quanto à esfera do consumo, as novas formas de produção das empresas, bem como as mudanças comportamentais dos indivíduos no mercado (Portilho, 2005). O mesmo pode ser alcançado pelo compartilhamento de responsabilidades, em meio a uma nova atuação em todas as esferas - econômicas, sociais e políticas, representadas genericamente pelo governo, empresas e demais atores da sociedade, enfim, por cada indivíduo-cidadão que possua a autonomia e o entendimento quanto a essa prática (Cortez \& Ortigoza, 2007; Panarotto, 2008). Para tanto, Jackson (2004) indica que não se deve apenas consumir menos, mas diferente e eficientemente.

Com essa visão, diferentes formas de consumir, voltadas para a sustentabilidade, podem ser identificadas na literatura. Como se pode observar na Figura 1 a seguir, a partir de uma perspectiva sequenciada de práticas responsáveis inerentes ao consumo, discute-se a existência inicialmente do consumo verde, passando para o consumo consciente e chegando ao consumo sustentável, numa ideia de hierarquia entre os mesmos (Silva, 2011). A partir dessa visão entre esses tipos de consumo a complexidade é visualizada numa sequência de atribuições complementares, na qual as ideias de maior quantidade de variáveis facilita o alcance de um novo paradigma de consumo.

Ao levar em consideração a visão ampla conferida ao consumo sustentável, segundo Silva (2012), o mesmo pode ser compreendido e conceituado como o padrão de consumo resultante de inter-relações sociais sob a perspectiva de interação política entre diferentes atores sociais direcionados ao alcance do desenvolvimento sustentável. Assim sendo, entende-se que para que seja posto em prática esse padrão sustentável de consumo é necessário considerar as relações de influência que diferentes stakeholders possuem sobre o consumo, no qual individualmente cada um deve assumir a identidade de seus papéis tornando-o mais articulado para com outros atores. Essa seria a principal distinção entre os tipos de consumo, o verde é ambiental, o consciente é individual e o sustentável é coletivo a partir das relações. Para ficarem mais claras essas diferenças busca-se um aprofundamento maior. 


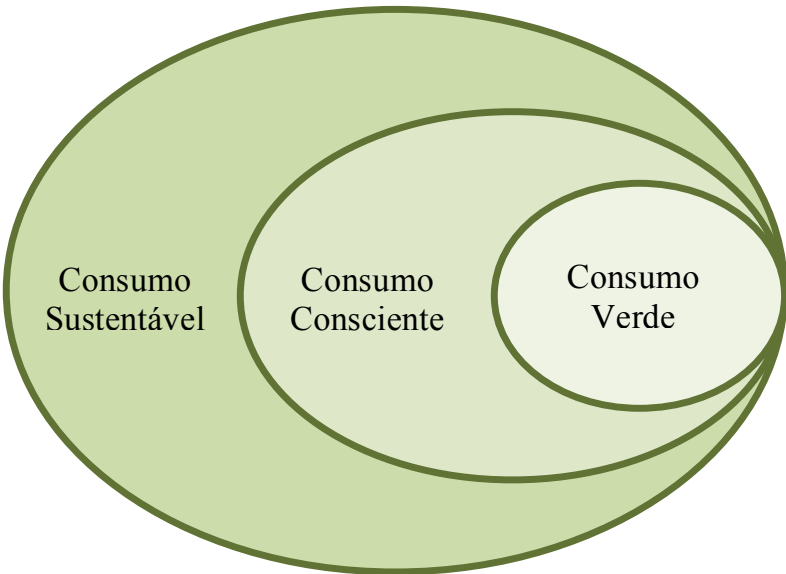

Figura 1 - Hierarquização das práticas responsáveis de consumo Fonte: Silva (2011, p.31)

\subsection{Consumo Consciente}

Entendendo que o indivíduo pode desenvolver diferentes papéis na sociedade como: a escolha por empresas que possuam antecedentes positivos e que não gerem um impacto negativo sobre o meio ambiente; a tomada de decisão correta no momento do voto em uma eleição; um comportamento consciente no momento de sua compra; entre outros, percebe-se que dentro deste contexto ele pode ser assumido como o mais importante, e o responsável pelo primeiro passo, nesse processo de mudança para um novo paradigma. Todavia, diante das muitas pressões e barreiras que lhe são oferecidas, o mesmo prefere se acomodar, em sua maioria, e seguir as tendências que são apresentadas, sem uma preocupação com futuro.

A partir das formas de consumo apresentadas anteriormente, a contribuição individual mais direta envolve o consumo verde, o qual se apresenta como o mais possível de ser efetivado. A ideia básica para essa prática de consumo envolve considerar especificamente o impacto ambiental do produto/serviço consumido (Gilg, Barr \& Ford, 2005; Portilho, 2005). De acordo com Portilho (2005), o consumidor verde deixa de considerar apenas as variáveis preço/qualidade, e acrescenta em seu processo de escolha a variável ambiental (como ocorre com o produto orgânico e o material reciclado). Isso ocorre a partir de um modelo de compra recursivo e complementar, que segundo Young, Hwang, McDonald \& Oates (2010), tem como etapas: (1) valores e conhecimento do verde; (2) critério verde de compra; (3) observar os facilitadores e as barreiras; (4) a compra verde; e (5) os feedbacks.

À medida que essa 'visão verde' assume uma maior amplitude, por considerar outros aspectos em torno da produção, distribuição e venda dos produtos/serviços, surge então um consumo mais responsável. Pensando nesta perspectiva e focando os aspectos de mercado, discute-se que surge um cidadão-consciente, consumidorcidadão ou cidadão socialmente responsável (Dobson, 2003; Eddine, Vetorazzi \& Freitas, 2008; Santos et al., 2008; Silva, Corrêa, Costa, Albuquerque, \& Almeida, 2012; Spaargaren \& Oosterveer, 2010; Vieira, 2010). Assim, diz-se que o consumo consciente efetiva-se ao ser levado em consideração os impactos provocados pelo consumo, buscando maximizar os impactos positivos e minimizar os negativos de acordo com os princípios da sustentabilidade (Instituto Akatu, 2001).

Corroborando Fabi, Lourenço e Silva (2010, p. 6) ratificam o conceito do Instituto Akatu ao indicar que o consumo consciente pode ser considerado como "o ato ou decisão de compra ou uso de serviços, de bens industriais ou naturais, praticado por um indivíduo, levando em conta o equilíbrio entre satisfação pessoal, as possibilidades ambientais e os efeitos sociais de sua decisão". De forma complementar, Santos et al. (2008) discutem o consumo consciente como um ato de cidadania, com a busca pelo equilíbrio entre a satisfação pessoal, o impacto de seu consumo no meio ambiente e o bem-estar da sociedade. Com isso, percebe-se que de fato há prática de consumo verde, mas com preocupações mais complexas.

Assim, como destacam De Toni et al. (2010, p.02), “compreender a imagem sobre o consumo consciente é um pressuposto básico para entender as atitudes do consumidor em relação à compra e ao consumo socialmente responsável". Entretanto, para Dobson (2003), para que esse novo comportamento de consumo possa ser efetivo, surgem como dificuldades: a influência dos custos da internalidade dos impactos ambientais e sociais, provavelmente repassados aos preços dos produtos; a existência de motivações psicológicas e sociológicas e outras influências, como: acessibilidade, disponibilidade, conveniência, aspiração, identidade e outras; a percepção da magnitude dos problemas (e as considerações dos demais) que implica em mudança do comportamento individual, e rompe sentimentos como o egoísmo.

Nesse sentido, segundo Wu, Cutright \& Fitzsimons (2011), um indivíduo necessita de autoconhecimento e autodescoberta sobre a sua prática de consumo tradicional, uma vez que a partir de um processo de aprendizagem cada vez mais consegue se adaptar a novas práticas cotidianas. Com essa ideia, se houver um direcionamento do comportamento do indivíduo para a sustentabilidade é possível uma maior sensação de pertencimento e contribuição para uma mudança social. Para Feital, Spers, Novaes Netto, Spers e Ponchio 
(2008, p.05), “a mudança de comportamento do consumidor é um processo que exige a sensibilização e mobilização social e, para esse processo, os meios de comunicação são fundamentais atuando junto ao público, mobilizando a consciência e ação dos consumidores".

A partir das considerações desses atores entende-se que são muitas as ações e mudanças que envolvem e incorporam o consumidor para uma prática mais responsável de consumo. A partir disso, além das ações a serem realizadas por outros atores na construção de um contexto macro de responsabilidade, percebe-se como necessária a criação de escalas que demonstram tanto as ações individuais por meio do consumo consciente quanto coletivas pelo consumo sustentável, tornando clara a distinção entre os tipos. Assim sendo, como discutido até então, para mensurar o consumo de uma população, instrumentos de avaliação são necessários à medida que convergem variáveis representativas de determinada situação, em relação a diferentes tipologias e confusões que podem existir entre as mesmas.

\subsubsection{Instrumentos de avaliação do consumo consciente: uma proposta de integração}

O consumo consciente pode ser avaliado através de características como: a cultura em que a sociedade está inserida, o poder aquisitivo das pessoas e o seu estilo de vida, questões éticas transmitidas para a sociedade (Silva \& Gómez, 2010). Para Young et al. (2010), podem ser observados ainda a falta de informação e a personalidade, que ao influenciarem na busca pelo consumo verde, estão diretamente relacionados com o consumo consciente. De acordo com essas características, percebe-se que a prática educacional pode contribuir para que o consumo seja mais sustentável, equilibrando as suas qualidades para a sustentabilidade (Silva \& Gómez, 2010). A partir de um levantamento, foram selecionados três instrumentos que de forma complementar apresentam características propensas à mensuração do consumo consciente, são eles: o Greendex, o do Instituto Akatu e o Ecological Footprint Method.

Durante a realização das pesquisas teóricas, houve dificuldade na identificação desses instrumentos tendo em vista que a confusão entre os termos sobre consumo e sustentabilidade ainda é muito observada, como já foi mencionado. Isso ocorreu, principalmente, nos trabalhos da National Geographic (2010a) e de Ribeiro e Veiga (2011), os quais se apresentam como instrumentos que podem ser utilizados para medir o consumo sustentável, mas que na verdade tratam especificamente da avaliação do consumo consciente. Essas variações foram levadas em consideração desenvolvimento deste estudo. Assim, os instrumentos selecionados apesar de alguns momentos possibilitarem o entendimento de aspectos mais amplos, foram utilizados no sentido de contribuir para a articulação de indicadores exclusivos ao consumo consciente.

Assim, o Ecological Footprint Method foi selecionado, pois o mesmo visa o estudo do impacto do ser humano sobre a capacidade de carga, numa perspectiva tanto individual como por localidade (Feitosa, Cândido \& Firmo, 2010; Gómez, Parísio, Castillo \& Santos, 2009; Wackernagel \& Rees, 1996), contribuindo com a proposta. Proposto por Wackernagel e Rees (1996), o modelo é descrito como uma ferramenta que contabiliza e faz a transformação do consumo da matéria-prima e energia de um sistema e o converte em áreas produtivas de terra ou água. A pegada ecológica, como é conhecida, pode ser estimada a partir das implicações de cada tipo de consumo ou recursos extraídos da natureza, no qual para cada item consumido existe uma área de terra para suportar os impactos da população (Gómez et al., 2009).

O modelo contrasta o consumo dos recursos pelas atividades humanas com a capacidade de suporte da natureza e mostra se seus impactos no ambiente global são sustentáveis a longo prazo. Ele também possibilita que se estabeleçam comparações entre indivíduos, cidades e nações (Feitosa, Cândido \& Firmo, 2010; Gómez et al., 2009). Neste sentido, para determinar a área total requerida para suportar determinado padrão de consumo, as implicações em termos de utilização de terra devem ser estimadas. Como não é possível estimar a demanda por área produtiva para provisão, manutenção e disposição de milhares de bens de consumo, os cálculos se restringem às categorias mais importantes e a alguns itens individuais.

Outro instrumento selecionado foi o Greendex. A partir das variáveis de mensuração que resulta de uma pesquisa internacional desenvolvida pela National Geographic em parceria com a GlobeScan, desde 2008, identifica-se que os objetivos do instrumento são: monitorar o progresso da população para um consumo ambientalmente sustentável; estabelecer medidas quantitativas do comportamento do consumidor; e também conciliar consciência ambiental e desenvolvimento (National Geographic, 2010b). Estruturalmente, é composto por um meta-índice composto por quatro sub-índices relacionados à habitação, transporte, alimentação e consumo de bens (separados em duráveis e não-duráveis). Esse último considera as compras e o descarte dos produtos (National Geographic, 2010a).

Semelhante à estrutura da pegada ecológica, no Greendex cada participante recebe uma pontuação que reflete o impacto ambiental de seu consumo. As atividades que têm um maior impacto no escore do Greendex são aquelas que possuem maiores custos ou benefícios ambientais, como: beber água de garrafa, dirigir carro sozinho ou consumir carne diariamente. Em contrapartida, das atividades que possuem menor impacto tem-se: usar transporte público e consumir alimentos cultivados na sua região. No entanto, o Greendex não considera as influências geográficas e conjunturais (cultura, religião) sobre o comportamento, tão pouco as condições climáticas em que os entrevistados vivem. Têm-se então lacunas que permitem a agregação de outros indicadores na busca por uma melhor maneira de avaliar tal prática de consumo, como por exemplo, a geração de resíduos e utilização de material reciclado.

Além destes instrumentos, o que se apresentou como aquele focado exclusivamente no consumo consciente e mais apropriado ao contexto brasileiro foi o do Instituto Akatu. No ano de 2007 o Instituto 
desenvolveu um estudo sobre o comportamento de consumo no contexto brasileiro e, Silva et al. (2012) desenvolveram uma pesquisa focando seus indicadores, o que ratifica a possibilidade de utilizá-lo como base para se estudar aspectos voltados para uma população. A partir dos indicadores apresentados no instrumento, percebe-se que o objetivo principal do Instituto Akatu é que haja uma discussão sobre os impactos positivos e negativos do consumo, para que o consumidor não seja somente um espectador dos problemas que o consumo causa, mas também se torne um ator que procura soluções.

O Instituto propicia a auto avaliação do consumo consciente a partir de um questionário online e é composto por cinquenta perguntas (http://www.akatu.org.br/), que permitem ao consumidor identificar o estágio de consciência na sua prática de consumo. O resultado facilita ao consumidor fazer uma comparação do seu comportamento enquanto consumidor em relação ao comportamento da população brasileira (Instituto Akatu, 2007). Assim, a partir desses instrumentos, pode-se observar a articulação de indicadores a partir da Figura 2, a qual leva em consideração a busca por uma complementaridade entre as diferentes variáveis no sentido de um entendimento global do consumo consciente.

\begin{tabular}{|c|c|c|}
\hline $\begin{array}{l}\text { Critérios } \\
\text { analisados }\end{array}$ & Indicadores de Consumo Consciente & $\begin{array}{l}\text { Perspectiva } \\
\text { Teórica }\end{array}$ \\
\hline \multirow{14}{*}{$\begin{array}{l}\text { Hábitos de } \\
\text { poupança }\end{array}$} & Como melhor se descreve seus gastos e hábitos de poupança & \multirow{40}{*}{$\begin{array}{l}\text { Feitosa, Cândido e } \\
\text { Firmo (2011); } \\
\text { Gómez et al. } \\
\text { (2009); Instituto } \\
\text { Akatu (2007); } \\
\text { National } \\
\text { Geographic } \\
\text { (2010a; 2010b); } \\
\text { Ribeiro e Veiga } \\
\text { (2011); } \\
\text { Wackernagel e } \\
\text { Rees (1996); Silva } \\
\text { et al. (2012). }\end{array}$} \\
\hline & Evita deixar lâmpadas acesas em ambientes desocupados & \\
\hline & Fecha a torneira enquanto escova os dentes & \\
\hline & Fecha o chuveiro enquanto se ensaboa & \\
\hline & Desliga aparelhos eletrônicos quando não está usando & \\
\hline & Costuma planejar as compras de alimentos & \\
\hline & Costuma pedir nota fiscal quando faz compras & \\
\hline & Costuma planejar compra de roupas & \\
\hline & Costuma utilizar o verso de folhas de papel já utilizadas & \\
\hline & Espera os alimentos esfriarem antes de guardar na geladeira & \\
\hline & Utiliza eletrodomésticos com rótulos de eficiência energética & \\
\hline & Utiliza energia renovável & \\
\hline & Diminui sua utilização de água & \\
\hline & Não liga o ar condicionado diariamente para poupar energia & \\
\hline \multirow{10}{*}{$\begin{array}{l}\text { Moradia e } \\
\text { Transporte }\end{array}$} & Quantas pessoas vivem na casa; & \\
\hline & Quantos quartos existem na casa & \\
\hline & $\begin{array}{l}\text { Realizou reforma ou pretende para possuir maior eficiência } \\
\text { doméstica }\end{array}$ & \\
\hline & $\begin{array}{l}\text { Leva em conta a proximidade e a facilidade de acesso entre } \\
\text { meus locais de moradia, trabalho e estudo, e procuro reduzir } \\
\text { meus deslocamentos pela cidade }\end{array}$ & \\
\hline & $\begin{array}{l}\text { Dirige veículos motorizados (carro popular, mini van, } \\
\text { caminhão) }\end{array}$ & \\
\hline & Dirige sozinho um carro ou caminhão & \\
\hline & Utiliza transporte público & \\
\hline & Viaja de avião & \\
\hline & Anda a pé ou de bicicleta & \\
\hline & Possui fogão, água morna, ar condicionado & \\
\hline \multirow{6}{*}{$\begin{array}{l}\text { Consumo de } \\
\text { bens } \\
\text { (sustentáveis } \\
\text { ou orgânicos) } \\
\text { e alimentos }\end{array}$} & Consome alimentos importados & \\
\hline & Consome galinha & \\
\hline & Consome carne & \\
\hline & Consome frutos do mar & \\
\hline & Consome frutas e vegetais & \\
\hline & Consome água de garrafa & \\
\hline \multirow{7}{*}{$\begin{array}{l}\text { Origem de } \\
\text { produtos, } \\
\text { publicidade } \\
\text { feita pelas } \\
\text { empresas, } \\
\text { critério de } \\
\text { compras }\end{array}$} & Consome alimentos cultivados na sua região & \\
\hline & Consome alimentos que você plantou & \\
\hline & Lê o rótulo atentamente antes de decidir a compra & \\
\hline & $\begin{array}{l}\text { Procura passar ao maior número possível de pessoas as } \\
\text { informações que aprende sobre empresas e produtos }\end{array}$ & \\
\hline & $\begin{array}{l}\text { Mobiliza-se para incentivar as empresas a prevenir ou corrigir } \\
\text { os danos ao meio ambiente causados por suas atividades }\end{array}$ & \\
\hline & $\begin{array}{l}\text { Pratica e incentiva o consumo de produtos que apoiem ações } \\
\text { de inclusão social ou de proteção ao meio ambiente }\end{array}$ & \\
\hline & $\begin{array}{l}\text { Costuma deixar de comprar produtos de empresas como } \\
\text { punição por terem feito algo prejudicial à sociedade ou ao } \\
\text { meio ambiente }\end{array}$ & \\
\hline \multirow{3}{*}{$\begin{array}{l}\text { Geração e } \\
\text { gestão de } \\
\text { resíduos }\end{array}$} & $\begin{array}{l}\text { A família separa o lixo para reciclagem (lata, papel, vidro, PET, } \\
\text { garrafas). }\end{array}$ & \\
\hline & $\begin{array}{l}\text { Preocupa-se em usar recursos de modo que não tragam } \\
\text { prejuízos para a sociedade e ao meio ambiente }\end{array}$ & \\
\hline & $\begin{array}{l}\text { Apoia campanhas de outras ações que incentivem as pessoas } \\
\text { para a reciclagem dos materiais, redução do lixo e reutilização } \\
\text { dos produtos. }\end{array}$ & \\
\hline
\end{tabular}

Figura 2 - Articulação de um conjunto de indicadores de consumo consciente 
Como podem ser observados no Quadro anterior, 40 indicadores foram articulados a partir dos instrumentos aqui discutidos de modo tal que permita a verificação do consumo consciente de determinada população, que no caso deste artigo, será realizada no município de Recife/PE. Trabalhar tais indicadores de forma integrada permite uma melhor visão de práticas em todas as áreas estudadas (critérios), de modo tal que se perceba a contribuição que os indivíduos enquanto consumidores conscientes fornecem para o alcance do consumo sustentável na localidade, mesmo sabendo que outros atores devem se tornar atuantes. Assim, cada um dos critérios foi selecionado das ferramentas de análise existentes para que a ideia de articulação proposta pudesse ser efetivada.

Com isso, o critério Hábitos de Poupança, selecionado do Ecological Footprint Method, é caracterizado como o conjunto de ações pontuais que, apesar de estarem relacionadas com as práticas cotidianas e possíveis de serem praticas, estão preocupadas com a economia de diferentes recursos visando à redução do impacto ambiental. Segundo o Instituto Akatu (2007, p.13), tais ações podem ser consideradas como "práticas que pressupõem o benefício direto para o indivíduo, considerando o não desperdício dos recursos, com retorno imediato e de curto prazo". No que se refere ao critério Moradia e Transporte, selecionado do Greendex, o mesmo busca representar a preocupação com o deslocamento e habitação num sentido de otimização racional dos reflexos de suas ações individuais para uma mudança maior.

Outro critério apresentado - Consumo de bens e alimentos (sustentáveis ou orgânicos), selecionado do Greendex, busca a sensibilização no plano do consumo bem planejado, que considera a construção e retorno no médio e longo prazo. Ao se analisar, origem do produto, critérios de compra e publicidade, selecionado do Instituto Akatu, identifica-se a possibilidade de mobilização do indivíduo diante das causas da sustentabilidade e responsabilidade social corporativa uma das premissas do consumo consciente (Instituto Akatu, 2007). Desse modo, fica claro que surgem aspectos relacionados aos produtos e informações, que quando melhor reconhecidos, podem ser aproveitados e interferir numa prática mais sustentável.

O último critério apresentado - Geração e gestão de resíduos, utilizado a partir dos indicadores do Ecological Footprint Method e Instituto Akatu, indica que se deve começar a levar em consideração práticas inerentes ao descarte, reuso e reaproveitamento de materiais em relação aos comportamentos dos indivíduos. Para que haja uma visão correta e clara dos resultados, a análise de todos os critérios, e de seus respectivos indicadores, deve ser realizada de forma complementar e inter-relacionada, uma vez que no todo se discute sobre o consumo consciente. Como já indicado, foca-se no consumo consciente que ao englobar o consumo verde contribui positivamente para a efetivação do consumo sustentável. No entanto, tais critérios ainda apresentam pouca consistência teórica, a qual necessita ser mais aprofundado a partir de articulação realizada. Com essa noção, a seguir apresentam-se os procedimentos utilizados para a pesquisa. Assim, torna-se facilitada a análise efetiva do consumo consciente.

\section{Procedimentos Metodológicos}

Para atender ao objetivo desse artigo, no que se refere à identificação do comportamento de consumo consciente da população de Recife/PE, após a articulação de um conjunto de indicadores anteriormente realizada, foi utilizada na pesquisa uma abordagem quantitativa, de modo a realizar uma visualização ampla sobre as características do fenômeno (Richardson, Peres, Wanderley, Correia \& Peres, 2008). Para tanto, assume-se um caráter descritivo, de acordo com a pesquisa bibliográfica e de campo. Após a identificação e articulação teórica dos indicadores utilizados na pesquisa, procedeu-se o processo de elaboração de questionário, de acordo com a seleção nos três instrumentos selecionados, com o qual se realizou uma pesquisa do tipo survey para identificar as características da população (Malhotra, 2006).

Para tanto, o questionário foi elaborado a partir do Greendex, do Instituto Akatu e do Ecological Footprint Method (Instituto Akatu, 2007; National Geografic, 2010a; Wackernagel \& Rees, 1996). Inicialmente buscou-se uma aproximação entre os indicadores para identificar quais possuíam semelhança. Num segundo momento, buscou-se agrupar diferentes itens de acordo com os critérios de análise utilizados, ou seja, dentro de dimensões específicas de análises. Após esse agrupamento, a forma de mensuração levou em consideração o perfil de cada item, existindo possibilidade de uma análise qualitativa (como o número de pessoas e quartos na casa), frequência (como utilizar transporte público e dirigir carro sozinho), bem como a partir de uma escala de concordância do tipo Likert de cinco pontos.

Para uma melhor identificação das informações necessárias, o questionário foi dividido em duas partes principais. A primeira delas foi referente ao perfil e estilo de vida da população, considerando questões como gênero, faixa etária, escolaridade, dentre outras. A segunda parte do questionário identificou os hábitos de consumo e a sensibilidade do respondente às diversas variáveis de acordo com a articulação realizada anteriormente. O universo escolhido foi a população do município de Recife/PE, e o procedimento para coleta das informações foi realizado por meio de entrevista presencial (em mercados públicos, universidades, órgãos públicos, feiras livres, condomínios, dentre outros) e on-line, utilizando o instrumento elaborado, após a realização de um pré-teste presencial com vinte pessoas.

Assim, foram entrevistados residentes das seis Regiões Político-Administrativas (RPAs) de Recife/PE, entre Abril e Junho de 2011, por meio de uma amostragem não probabilística considerando o gênero e a faixa etária, e um processo de coleta intencional para atender aos estratos definidos. Enquanto uma das principais cidades brasileiras, a capital pernambucana, possuía uma população de 1.561 .663 habitantes (Instituto Brasileiro de Geografia e Estatística [IBGE], 2009), no qual 724.712 do sexo masculino e 836.951 do sexo feminino. Assim, 
com um nível de confiança de 95\%, 601 questionários foram aplicados. Como a população investigada é maior que 100.000 indivíduos, torna-se indispensável a realização da correção do cálculo da amostra. Justificando assim a realização de uma pesquisa do tipo survey.

Após coletados, os dados obtidos foram tabulados e analisados no software SPSS ${ } 17.0$ instalado no laboratório do PROPAD/UFPE, no qual foram realizadas análises estatísticas. Foram realizadas análises descritivas para informações macro como aspectos demográficos e as frequências dos indicadores, bem como análises inferenciais para identificar a diferença nas médias dos respondentes. Para tanto, quanto ao gênero foi realizado o teste t para avaliar a significância de diferenças entre os dois grupos, já para a renda familiar e a escolaridade, pela maior quantidade de grupos, o teste ANOVA one-way (Hair, Black, Babin, Anderson \& Tatham, 2009). Após gerar as informações, utilizou-se o software Excel 2007 para melhor apresentação dos resultados encontrados. Assim sendo, são apresentados a seguir os principais achados gerados nessa pesquisa para o reconhecimento do perfil da população estudada.

\section{Apresentação e discussão dos resultados}

Para o entendimento da aplicabilidade dos indicadores articulados nesta pesquisa, esta seção apresenta os resultados empíricos provenientes do processo de coleta de dados. A seguir são identificados: (1) as informações sociodemográficas; (2) o comportamento de consumo consciente dos respondentes; e (3) uma análise inferencial a partir da diferenciação de médias buscando identificar diferenças significativas nas respostas.

\subsection{Perfil Sociodemográfico dos Entrevistados}

Para o reconhecimento dos comportamentos específicos à população recifense quanto ao consumo consciente, fez-se necessário identificar os aspectos envolvidos com a temática, dentre os quais: faixa etária, renda familiar e escolaridade. Isso porque ainda existem dúvidas sobre a influência que essas variáveis possuem sobre o comportamento, principalmente relacionadas ao consumo consciente. Com isso, busca-se demonstrar relações que possam contribuir com esse entendimento. Compreendendo de maneira relacionada esses aspectos, foi possível verificar de forma mais clara qual o perfil dessa população para, em seguida, identificar características do consumo consciente. Como se pode observar a partir da Figura 3, a renda predominante na cidade do Recife é de até dois salários mínimos correspondendo a $27 \%$ da população, o que pode influenciar nas respostas apresentadas.

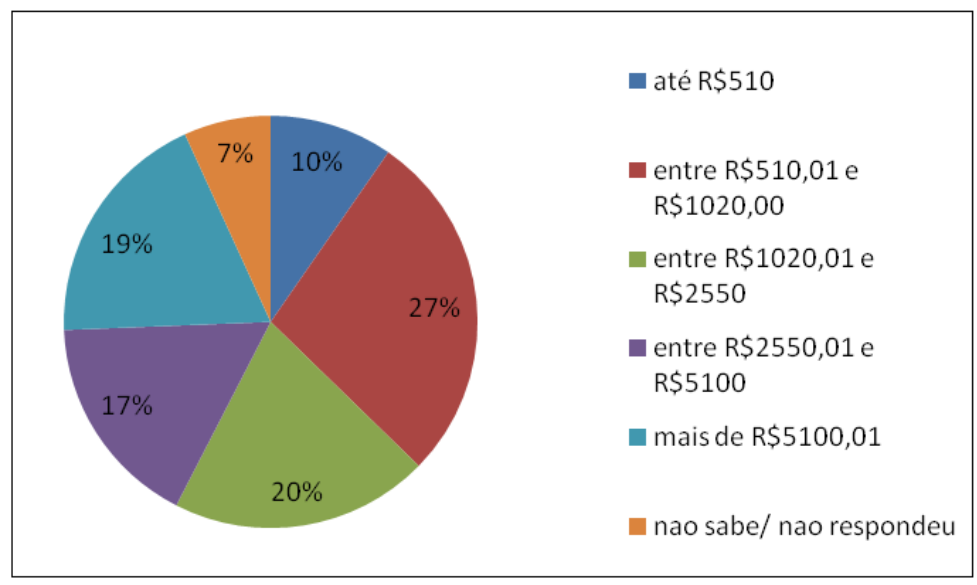

Figura 3 - Renda Familiar da população pesquisada Fonte: Dados da pesquisa (2011)

Como indicado nos procedimentos metodológicos quanto ao gênero a população maior é feminina, tal dado poderia ser levado em consideração nas análises, no entanto, como será apresentado a seguir, as respostas demonstram haver pouca diferença significativa entre as respostas apresentadas. Essa é uma informação importante que demonstra haver envolvimento coletivo quanto à busca pela sustentabilidade. A faixa etária da amostra em sua maioria encontra-se dos 20 aos 39 anos, mostrando um perfil jovem que pode vir a se preocupar mais com o tema pesquisado. Noutra perspectiva, a educacional, Silva e Gómez (2010) indicam que para a prática do consumo consciente esse é um dos aspectos que mais deve ser levado em consideração, com isso percebeu-se nos entrevistados que a maioria $(30,3 \%)$ encontra-se com o ensino superior incompleto, como observado na Figura 4.

Esse perfil sugere que haja uma preocupação maior com a busca por uma modificação em seu comportamento, já que teoricamente quanto mais informações se recebem mais politizado e consciente de suas práticas o indivíduo-cidadão se encontra. Como demonstrado a seguir, existem diferenças significativas entre as médias dos respondentes no que se refere ao nível de escolaridade desses. Quando questionados sobre moradia, $57,9 \%$ dos entrevistados dizem que moram com três ou quatro pessoas e $57,2 \%$ responderam que consideram sua residência um pequeno apartamento ou casa com quatro quartos ou menos. Essas informações 
sugerem que o perfil da população pode ser considerado como homogêneo em suas características, tornando mais facilitada as inferências que forem realizadas posteriormente.

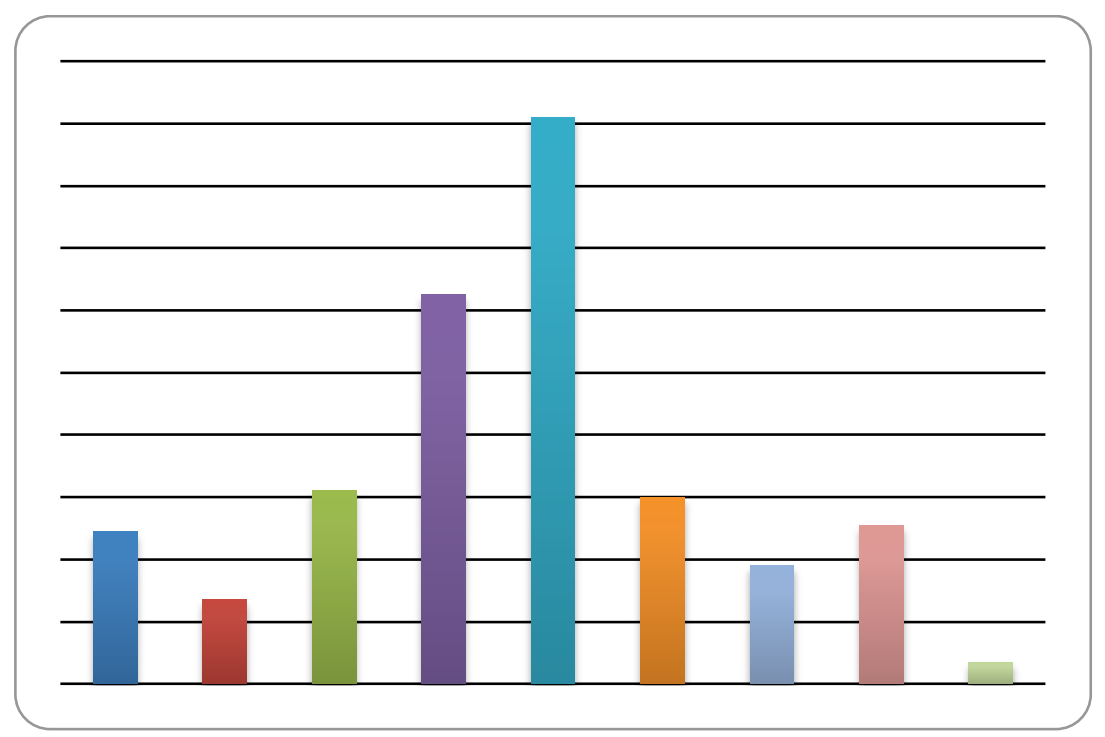

Figura 4 - Grau de Escolaridade da população pesquisa Fonte: Dados da pesquisa (2011)

Quando perguntados a respeito dos seus hábitos de transporte, 57,9\% dos entrevistados disseram que não dirigem. Esse fato pode estar relacionado com a renda da população pesquisada, como foi visto anteriormente, que é de até dois salários mínimos o que indica que com tal renda os consumidores não terem condições de adquirir um automóvel. Como apresentado a seguir, principalmente quanto aos indicadores relacionados com transporte, existe diferença nas médias entre os respondentes quanto à renda familiar. Com isso, esses indivíduos contribuem mesmo que de forma alheia a sua vontade com a redução na quantidade de combustíveis fósseis que são consumidos nas cidades, principalmente pela quantidade de veículos automotores que circulam diariamente em Recife.

Em relação aos hábitos de poupança, a maioria dos respondentes $(47,8 \%)$ responderam que vivem dentro das suas possibilidades, enquanto $25,5 \%$ gasta toda a sua renda e $25,5 \%$ sempre economiza para o futuro. Essas informações são singulares, à medida que cada um dos respondentes demonstra sua percepção em relação ao contexto que lhe é apresentado. De forma complementar buscando entender como os mesmos agiriam a partir de uma mudança sem suas rendas, percebeu-se que $64,4 \%$ alegaram que, se suas rendas fossem maiores os produtos sustentáveis seriam privilegiados. Dessa informação pode-se inferir que um dos motivos que a população não consome mais produtos sustentáveis é a sua insatisfação com a renda ou mesmo falta de envolvimento global com as questões da sustentabilidade.

Quanto ao estilo de alimentação dos participantes da pesquisa, percebeu-se que 40,6\% dos entrevistados se consideram onívoros, que são aqueles que consomem todos os alimentos sem restrições, incluindo carne, frutos do mar, laticínios, vegetais e grãos. Esse tipo de dieta está em consonância com o perfil nacional, em que a população consome todos os alimentos sem restrições. Para que se busque uma prática de consumo mais consciente, quanto menos impactos negativos os elementos consumidos possuem melhor. Com isso, percebe-se que as informações até então apresentadas mostram uma população jovem e com pouca renda, o que pode contribuir para informações mais favoráveis à definição de uma população consciente, de acordo com as discussões a seguir.

\subsection{Consumo Consciente da População do Recife}

Na busca pela assimilação das características da população recifense junto à ideia de consumo consciente que vem sendo trabalhada, a pesquisa identificou alguns comportamentos desenvolvidos cotidianamente pelos entrevistados. Com isso, buscou-se dar destaque para os indicadores que estão mais bem representados nos resultados, para identificação do perfil como um todo. Dentre os vários questionamentos que foram realizados aos recifenses, um conjunto deles buscou refletir sobre pequenas ações que podem ser realizadas para que o impacto do homem no meio ambiente possa ser reduzido. Salienta-se que esses indicadores demonstram um posicionamento efetivo dos respondentes ao consumo consciente, os quais muitas vezes necessitam de contribuições de outros atores. Assim sendo, na Tabela 1 estão apresentadas as respostas que melhor caracterizam as práticas do cotidiano dessa população.

Pode-se perceber que o perfil do consumidor recifense demonstra muita preocupação em relação ao cuidado em não deixar aparelhos eletrônicos e lâmpadas acesas quando o aparelho ou o local não estão sendo utilizado, o que sugere preocupação com a economia de energia elétrica. É importante ressaltar que esse é um hábito que tem impacto direto nas despesas mensais das famílias, ou seja, o fato não é apenas causador de impacto ambiental positivo, mas também de impacto econômico, e isso pode estar associado ao seu perfil e sua 
renda familiar. Dentro de um contexto de consumo sustentável, se esses resultados estiverem relacionados com informações da mídia ou mesmo da empresa que faz a distribuição da energia, existe uma tendência macro de mudança para toda a população.

\begin{tabular}{|c|c|c|c|c|c|c|}
\hline Variável & Nunca & Raramente & $\begin{array}{c}\text { Às } \\
\text { vezes }\end{array}$ & $\begin{array}{l}\text { Quase } \\
\text { sempre }\end{array}$ & Sempre & $\begin{array}{l}\text { Não } \\
\text { respondeu }\end{array}$ \\
\hline $\begin{array}{l}\text { Evita deixar lâmpadas acesas em ambientes } \\
\text { desocupados }\end{array}$ & 5,20 & 4,30 & 8,50 & 20,10 & 61,70 & 0,00 \\
\hline $\begin{array}{l}\text { Fecha a torneira enquanto escova os dentes } \\
\text { Fecha o chuveiro enquanto se ensaboa }\end{array}$ & $\begin{array}{c}3,30 \\
11,00\end{array}$ & $\begin{array}{l}4,00 \\
8,20\end{array}$ & $\begin{array}{c}9,80 \\
12,10\end{array}$ & $\begin{array}{l}12,30 \\
14,80\end{array}$ & $\begin{array}{l}70,00 \\
53,90\end{array}$ & $\begin{array}{l}0,00 \\
0,00\end{array}$ \\
\hline $\begin{array}{l}\text { Desliga aparelhos eletrônicos quando não está } \\
\text { usando }\end{array}$ & 5,00 & 9,20 & 12,30 & 18,10 & 55,20 & 0,20 \\
\hline $\begin{array}{l}\text { Costuma planejar a compra de alimentos } \\
\text { Costuma pedir nota fiscal quando faz compras } \\
\text { Costuma planejar compra de roupas }\end{array}$ & $\begin{array}{l}17,30 \\
14,30 \\
15,60\end{array}$ & $\begin{array}{l}11,50 \\
11,50 \\
12,80\end{array}$ & $\begin{array}{l}15,10 \\
21,30 \\
23,60\end{array}$ & $\begin{array}{l}17,10 \\
18,10 \\
16,10\end{array}$ & $\begin{array}{l}38,80 \\
34,60 \\
30,60\end{array}$ & $\begin{array}{l}0,20 \\
0,20 \\
1,20\end{array}$ \\
\hline $\begin{array}{l}\text { Costuma utilizar o verso de folhas de papel já } \\
\text { utilizado }\end{array}$ & 12,60 & 11,60 & 17,50 & 20,10 & 37,40 & 0,70 \\
\hline $\begin{array}{l}\text { Lê o rótulo atentamente antes de decidir a } \\
\text { compra }\end{array}$ & 14,00 & 18,80 & 22,60 & 14,80 & 29,80 & 0,00 \\
\hline A família separa o lixo para reciclagem & 43,10 & 17,80 & 15,60 & 7,20 & 16,30 & 0,00 \\
\hline $\begin{array}{l}\text { Espera os alimentos esfriarem antes de } \\
\text { guardar na geladeira }\end{array}$ & 9,80 & 10,80 & 13,00 & 14,60 & 51,10 & 0,70 \\
\hline $\begin{array}{l}\text { Procura passar ao maior número de pessoas as } \\
\text { informações que aprende sobre as empresas e } \\
\text { produtos }\end{array}$ & 10,60 & 18,50 & 26,50 & 14,80 & 29,10 & 0,50 \\
\hline
\end{tabular}

Tabela 1 - Comportamento do cotidiano da população entrevistada

Fonte: Dados da pesquisa (2011)

Além disso, percebe-se também que a maioria da população não tem o hábito de separar o lixo de suas casas para reciclagem, implicando negativamente na questão do consumo, pois sem a separação do lixo, há uma maior dificuldade de reciclá-lo ou reutilizá-lo. A partir desse aspecto percebe-se o quão necessário se faz do envolvimento de outros atores estimulando o consumo consciente, nesse caso recebe destaque o governo que por meio do incremento de uma coleta seletiva pode promover a reciclagem e criar novos hábitos de descarte, o que contribui diretamente com a redução dos impactos ambientais. No entanto, é preciso destacar que, assim como noutros municípios brasileiros, a coleta seletiva por parte da municipalidade é carente, ocorre em alguns bairros e outros não, com falta de informação à população.

Mas também têm que se reconhecer que cada vez mais empresas vêm promovendo a divulgação e prática da coleta seletiva, como é o caso das iniciativas locais das empresas ASA Indústria de Alimentos Ltda. responsável pela coleta de óleo de cozinha, os supermercados que possuem estações de reciclagem como a rede Pão de Açúcar e Wal-Mart, as unidades de atendimento ao consumidor da Companhia Pernambucana de Saneamento (COMPESA), e, a Companhia Energética de Pernambuco (CELPE). Além disso, em Recife, existem inúmeras associações de catadores legalizadas e que promovem coleta seletiva de papel, alumínio, vidro e outros materiais recicláveis. A cidade poderia buscar em outras como Porto Alegre, entender como se dá a coleta seletiva e buscar adaptar as suas necessidades.

Um dos aspectos que recebeu um maior destaque de acordo com os dados foram as variáveis 'fechar a torneira enquanto escova os dentes e, se ensaboa durante o banho', tiveram uma porcentagem muito alta de acordo com as respostas, $70 \%$ e 53,9\% respectivamente. Tal resultado pode ser vinculado ao intensivo processo de conscientização realizado na mídia, principalmente televisiva, a qual de forma simples demonstra a possibilidade de contribuição individual para uma mudança macro rumo a um consumo sustentável. Essas respostas estão relacionadas com a pergunta realizada noutro conjunto de variáveis, a qual se refere à utilização da água. A resposta apresenta preocupação da maioria dos entrevistados (31,9\%), mas que aponta discrepância de respostas, se os mesmos forem confrontados.

Essa ideia mostra uma preocupação que o recifense tem com a economia da água. Tal fato pode estar relacionado com os históricos de constantes cortes no abastecimento de água potável no município, assim como ocorreu no começo de 2013. Identifica-se que está em obras no Estado, a construção de novas barragens e sistemas de abastecimento de água para a Região Metropolitana do Recife, como afirma o presidente da COMPESA: "Décadas de racionamento desgastaram as nossas tubulações, que não foram feitas para ficar com água um dia e sem água no outro", afirmou. Para o presidente da companhia, "isso foi resultado da falta de investimento no setor de saneamento, principalmente nas décadas de 80 e 90 , e de falta de planejamento urbano". Espera-se uma mudança macro para um consumo sustentável.

Além das variáveis até então analisadas, percebe-se que para o consumo consciente de fato seja praticado é necessário que haja uma preocupação desse consumidor com relação ao que será comprado, isso foi observado com relação à compra de alimentos e roupas, o que indica que não há consumo incontrolável e despreocupado da população. Em se tratando do consumo de produtos fabricados com material reciclado $(39,8 \%)$ e, de produtos orgânicos $(38,6 \%)$ os entrevistados responderam escolher produtos que tenham essas características. No mercado como um todo ainda existe uma preocupação com relação sobre esses aspectos, uma vez que a relação custo-benefício dificulta um maior número de consumidores à compra. 
No que se refere a como o indivíduo vê o consumo, das respostas $77,7 \%$ considera que a origem dos produtos que consumimos é muito importante, isso porque sua produção pode ter causado danos para o meio ambiente e para a sociedade, e também foi apontado $(74,4 \%)$ que não só o governo tem condições de garantir o equilíbrio da sociedade e direcionar questões como eliminação da pobreza e proteção ao meio ambiente, corroborando com a questão central do consumo sustentável, em que as pessoas, empresas e governo atuam juntos para a promoção de uma sociedade mais sustentável. Ainda com um foco no indivíduo, a Tabela 2 apresenta informações que demonstram hábitos e comportamentos de consumo específicos, os quais agregados a outras variáveis contribuem diretamente ao consumo consciente.

\begin{tabular}{|c|c|c|c|c|c|}
\hline Variáveis & Nunca & Raramente & $\begin{array}{c}\text { Às } \\
\text { vezes }\end{array}$ & $\begin{array}{l}\text { Quase } \\
\text { sempre }\end{array}$ & Sempre \\
\hline Consome alimentos importados & 24,80 & 32,40 & 32,10 & 6,30 & 4,00 \\
\hline Consome alimentos cultivados na sua região & 3,80 & 6,30 & 22,30 & 24,00 & 43,40 \\
\hline Consome galinha & 2,00 & 4,50 & 21,10 & 30,30 & 41,80 \\
\hline Consome carne & 1,80 & 8,20 & 17,80 & 31,30 & 40,30 \\
\hline Consome frutos do mar & 6,00 & 17,50 & 35,40 & 21,60 & 19,10 \\
\hline Consome frutas e vegetais & 4,50 & 6,00 & 15,00 & 22,60 & 51,40 \\
\hline Consome alimentos que você plantou & 78,50 & 6,70 & 5,30 & 1,70 & 7,50 \\
\hline Consome água de garrafa & 6,50 & 5,80 & 13,10 & 13,10 & 60,90 \\
\hline Dirige sozinho um carro ou caminhão & 50,10 & 6,50 & 10,60 & 7,80 & 23,30 \\
\hline Utiliza transporte público & 13,00 & 15,10 & 14,00 & 10,80 & 46,90 \\
\hline Viaja de avião & 43,80 & 22,50 & 20,00 & 8,20 & 5,30 \\
\hline Anda a pé ou de bicicleta & 4,70 & 14,00 & 24,10 & 24,00 & 32,90 \\
\hline Diminui sua utilização de água & 10,80 & 10,00 & 28,30 & 18,30 & 31,90 \\
\hline
\end{tabular}

Tabela 2 - Comportamento e hábitos de consumo da população pesquisada

Fonte: Dados da pesquisa (2011)

Diante dos dados apresentados na Tabela 2 observa-se que grande parte da população entrevistada consome com frequência carne $(41,8 \%)$, galinha $(40,3 \%)$, frutas e vegetais $(51,4 \%)$, o que corrobora as informações sobre a dieta apresentadas na seção anterior, a qual mencionava que a maioria dos respondentes, de forma alinhada ao perfil brasileiro, possui um estilo de consumo onívoro. Ressalta-se que ao se analisar esses aspectos, existe um ponto que deve ser observado, o consumo de produtos que necessitam de muita água em sua produção, como o caso da carne, quanto mais se consome carne maior o impacto sobre o meio ambiente. Além dos outros vários aspectos, como a emissão gases poluentes e a falta de preocupação com o bem-estar animal, que são consequência dessa prática pecuária.

Além disso, percebe-se que 78,5\% dos entrevistados não têm como hábito plantar o seu próprio alimento, o que se explica por Recife ser considerada uma cidade de grande porte e ser totalmente urbana. Alternativas poderiam ser utilizadas, como pequenas hortas caseiras, as quais têm grande potencial de surgimento. A utilização do transporte público por parte de $46,8 \%$ dos respondentes ocorre sempre, o que pode estar relacionado com a baixa renda apresentada no perfil da população. Quando analisada a variável 'não liga o ar condicionado diariamente para poupar energia', percebe-se que 46,4\% dos respondentes estão voltados para uma economia de energia, o que se relaciona com a discussão antes realizada sobre economia de energia. Esses e outros aspectos podem ser mais bem observados na Tabela 3 a seguir, que apresenta as últimas variáveis analisadas.

\begin{tabular}{|c|c|c|c|c|c|}
\hline Variável & Nunca & Raramente & $\begin{array}{c}\text { Às } \\
\text { vezes }\end{array}$ & $\begin{array}{c}\text { Quase } \\
\text { sempre }\end{array}$ & Sempre \\
\hline Não liga o ar condicionado diariamente para poupar energia & 24,00 & 9,20 & 12,00 & 7,70 & 46,40 \\
\hline $\begin{array}{l}\text { Pratica e incentiva o consumo de produtos que apóiem ações de } \\
\text { inclusão social ou de proteção ao meio ambiente }\end{array}$ & 22,50 & 19,10 & 21,30 & 14,00 & 23,00 \\
\hline $\begin{array}{l}\text { Mobiliza-se para incentivar as empresas a prevenir ou corrigir os } \\
\text { danos ao meio ambiente causados por suas atividades }\end{array}$ & 43,40 & 21,60 & 14,30 & 8,80 & 11,60 \\
\hline $\begin{array}{l}\text { Costuma deixar de comprar produtos de empresas como punição } \\
\text { por terem feito algo prejudicial ao meio ambiente }\end{array}$ & 23,30 & 18,00 & 16,60 & 12,50 & 29,50 \\
\hline $\begin{array}{l}\text { Leva em conta a proximidade e a facilidade de acesso entre } \\
\text { meus locais de moradia, trabalho e estudo, e procuro reduzir } \\
\text { meus deslocamentos pela cidade }\end{array}$ & 11,80 & 11,60 & 17,30 & 20,60 & 38,40 \\
\hline $\begin{array}{l}\text { Preocupa-se em usar recursos de modo que não tragam prejuízos } \\
\text { para a sociedade e ao meio ambiente }\end{array}$ & 8,30 & 10,10 & 20,00 & 20,00 & 41,40 \\
\hline $\begin{array}{l}\text { Apóia campanhas de outras ações que incentivem as pessoas } \\
\text { para a reciclagem dos materiais, redução do lixo e reutilização } \\
\text { dos produtos }\end{array}$ & 14,10 & 13,50 & 16,30 & 16,00 & 39,90 \\
\hline
\end{tabular}

Tabela 3 - Comportamento e hábitos de consumo da população pesquisada

Fonte: Dados da pesquisa (2011)

Percebe-se nas informações apresentadas na ilustração, que alguns destaques podem ser realizados. A variável 'levar em conta a proximidade e a facilidade de acesso entre meus locais de moradia, trabalho e estudo, e procurar reduzir meus deslocamentos pela cidade', demonstra a busca de alternativas que diminuam o tempo do cidadão no trânsito, haja vista que, assim como em outras grandes cidades do país, Recife apresenta congestionamentos na maioria das principais ruas e avenidas, principalmente nos horários de maior movimentação. Numa perspectiva positiva, essa ideia pode estar relacionada com a preocupação de redução do 
impacto dos transportes no meio e uma contribuição efetiva da população nesse sentido. No entanto, como já mencionado, a infraestrutura de transporte público não tem condições, ainda, de contribuir favoravelmente nesse sentido.

Outra variável interessante de notar refere-se à última variável 'Apoiar campanhas de outras ações que incentivem as pessoas para a reciclagem dos materiais, redução do lixo e reutilização dos produtos', a qual aponta um resultado que contradiz os resultados na Tabela 1 anterior na qual a informação obtida é de que a maioria dos entrevistados não costuma reciclar seu lixo. Enquanto 39,9\% diz que apoia campanhas, 43,1\% dos entrevistados diz que nunca separa o lixo para reciclagem. E ainda no indicador 'Procurar passar ao maior número de pessoas as informações que aprende sobre as empresas e produtos' apresentado na Tabela 1 , um total de $29,10 \%$ dos entrevistados diz realizar tal prática sempre.

Essa ideia considera que quanto a essas variáveis o discurso é diferente da prática, considerando que a população tem o interesse de apoiar diferentes campanhas, que se envolve com um pensamento de mudança, todavia na efetivação do comportamento não o faz. Isso pode estar relacionado, a um controle de comportamento social, ter que falar positivamente sobre algo que interfere no coletivo, ou mesmo por falta de infraestrutura para que se comporte alinhado ao seu discurso. Além disso, ao se observar a Tabela 3 no tange a essa variável, existe uma heterogeneidade de respostas, o que de algum modo pode dar base para o entendimento dessa contradição com relação ao que de fato foi respondido.

Com isso, o que se percebe é que a população do Recife, de acordo com os indicadores de consumo consciente que foram articulados, possui um direcionamento para a prática de um comportamento consciente, em sua maioria, mas que por questões alheias as suas vontades não conseguem desempenhar bem suas atividades. Tal fato ressalta a necessidade de se buscar um consumo sustentável, no qual além do indivíduo, outros atores devem estar atuando na busca por modificações nas ações desenvolvidas. Como se pôde observar durante a pesquisa, muitas das atribuições pelo não comportamento pró-ativo foi direcionado para falhas por parte do governo e de empresas, o que ratifica a necessidade de mudança de comportamento.

Assim, o conjunto de indicadores agrupados para a realização dessa pesquisa a partir do Greendex, do Instituto Akatu e do Ecological Footprint Method, apresenta uma contribuição positiva para o estudo do consumo consciente de uma população sob a perspectiva do consumo sustentável, tendo em vista que o indivíduo tem seu papel de contribuição para um novo padrão, mas o mesmo enquanto consumidor não tem o poder de definir aspectos macro que são de responsabilidade das autoridades políticas, ou que envolvem os produtos e serviços ofertados na sociedade. Com isso, quanto mais discussões forem realizadas nesse sentido melhor para o surgimento de um novo paradigma de consumo e, por consequência, de desenvolvimento, voltado à sustentabilidade.

\subsection{Testes Estatísticos de Diferenciação de Médias}

A partir do entendimento do comportamento voltado de forma 'suave' ao consumo consciente, busca-se com os testes de diferenciação de média identificar se existem diferenças significativas nas respostas. Para tanto, foram utilizados dois testes: (1) teste t para análise das respostas do gênero, por haver apenas dois grupos; (2) teste ANOVA one-way para analisar as variáveis renda familiar e escolaridade. De forma geral, identificou-se que o gênero não apresenta diferenças significativas nas variáveis analisadas. Como são grupos independentes, caso as variâncias sejam iguais, deverá ser considerado o teste t homocedástico e, caso as variâncias sejam diferentes, o teste t a ser considerado é o heterocedástico para que se possa identificar uma diferença de média nas respostas de cada grupo de respondentes (Pereira, 2004). Assim, foram poucas as variáveis que demonstraram essa diferença.

Após essa classificação, observa-se o teste t em si, o qual considera ser necessário apresentar o Sig. (2tailed) $<0,05$, de acordo com o que indica Hair et al. (2009). Assim sendo, foi identificada nos resultados uma única variável heterocedásticas: 'Fecha o chuveiro enquanto se ensaboa' (Sig. Levene 0,000; Sig. (2-tailed) Masc. 0,022; Fem. 0,025), o que indica que homens e mulheres percebem de forma diferente o item. Já quanto as variáveis homocedásticas, foram identificadas: 'Desliga aparelhos eletrônicos quando não está usando' (Sig. Levene 0,216; Sig. (2-tailed) Masc. 0,004; Fem. 0,005); 'Costuma planejar as compras de alimentos' (Sig. Levene 0,182; Sig. (2-tailed) Masc. 0,001; Fem. 0,001); 'Consome frutos do mar' (Sig. Levene 0,792; Sig. (2tailed) Masc. 0,019; Fem. 0,019); 'Dirige sozinho carro ou caminhão' (Sig. Levene 0,056; Sig. (2-tailed) Masc. 0,000; Fem. 0,000).

De acordo com essas informações, entende-se que apenas nessas variáveis existem respostas significativamente diferentes, no que se refere às médias das respostas. Pelo fato de haver uma quantidade maior de mulheres respondendo, a tendência seria considerar que esse gênero possui maiores preocupações e maior sensibilidade que o masculino, além dessas se sentirem mais incomodadas com práticas insustentáveis. Como demonstram as análises, isso não pode ser assumido como um pressuposto de análise, uma hipótese para isso pode ser a quantidade de informações que atualmente vem sendo disseminadas, seja por empresas, pelo governo ou mesmo em campanhas publicitárias, tem alcançado de forma homogênea toda a audiência. Além disso, não existem evidências que continuem corroborando com essa visão.

No que se refere à renda familiar, utilizou-se a ANOVA como teste de diferenciação. Como se pode observar na Tabela 4, a seguir, do total de indicadores apresentados a partir da articulação teórica entre os três instrumentos de análise do consumo consciente, 13 deles apresentaram diferenças de médias entre os grupos 
da variável. Isso significa que para esses indicadores o nível de renda familiar interfere na realização ou não, na contribuição ou não dos respondentes para a sustentabilidade, de acordo com sua prática de consumo consciente. Assim, é interessante considerar que, sob determinados aspectos, sejam esses relacionados a uma infraestrutura específica ou estilo de vida do respondente, a renda tem influência sobre a sua realização total.

\begin{tabular}{|c|c|c|c|c|}
\hline Critérios & Indicadores de Consumo Consciente & $\begin{array}{c}\text { Sig. } \\
\text { Levene }\end{array}$ & F & $\begin{array}{c}\text { Sig. } \\
\text { (ANOVA) }\end{array}$ \\
\hline \multirow{5}{*}{ Hábitos de poupança } & Fecha o chuveiro enquanto se ensaboa & 0,001 & 4,763 & 0,000 \\
\hline & Desliga aparelhos eletrônicos quando não está usando & 0,000 & 2,409 & 0,035 \\
\hline & Costuma utilizar o verso de folhas de papel já utilizadas & 0,000 & 4,103 & 0,001 \\
\hline & $\begin{array}{l}\text { Espera os alimentos esfriarem antes de guardar na } \\
\text { geladeira }\end{array}$ & 0,000 & 3,533 & 0,004 \\
\hline & Diminui sua utilização de água & 0,114 & 3,761 & 0,002 \\
\hline \multirow{5}{*}{ Moradia e transporte } & Dirige sozinho um carro ou caminhão & 0,699 & 15,76 & 0,000 \\
\hline & Utiliza transporte público & 0,000 & 10,611 & 0,000 \\
\hline & Viaja de avião & 0,000 & 27,286 & 0,000 \\
\hline & Anda a pé ou de bicicleta & 0,000 & 9,072 & 0,000 \\
\hline & Possui fogão, água morna, ar condicionado & 0,000 & 70,509 & 0,000 \\
\hline \multirow{2}{*}{$\begin{array}{l}\text { Consumo de bens e } \\
\text { alimentos }\end{array}$} & Consome alimentos importados & 0,000 & 10,454 & 0,000 \\
\hline & Consome frutos do mar & 0,041 & 2,112 & 0,062 \\
\hline $\begin{array}{l}\text { Geração e gestão de } \\
\text { resíduos }\end{array}$ & $\begin{array}{l}\text { Preocupa-se em usar recursos de modo que não tragam } \\
\text { prejuízos para a sociedade e ao meio ambiente }\end{array}$ & 0,000 & 4,047 & 0,001 \\
\hline
\end{tabular}

Tabela 4 - Teste de diferença de média com relação a renda familiar

Como apresentado na Tabela 4, para que possam ser identificadas diferenças de média nas respostas, é necessário Sig. < 0,05, o que demonstra que pelo menos um par de grupos em relação às possibilidades possuem índices médios diferentes. Observa-se a existência de diferenças quatro dos cinco critérios (dimensões) de análise utilizados, o que sugere que no que se refere à origem do produto, a publicidade realizada pelas empresas e aos critérios de compra, a renda não apresenta influência direta. Das informações apresentadas, vale salientar o critério de transporte, pois todos os indicadores que contribuem para analisá-lo apresentam diferenças significativas nas respostas. Fato este que ratifica as inferências realizadas na parte descritiva dessas análises, ou seja, o poder aquisitivo influencia na utilização dos transportes.

Esse aspecto ainda fica claro no que se refere aos hábitos de poupança, isso pode ser analisado ao considerar que em busca de economias quanto à água ou energia, por exemplo, a população que apresenta uma menor renda tenha maior preocupação - a partir das médias identificadas nas diferentes variáveis, não apenas por isso afetar o meio ambiente, mas por entender que a poupança gradativa leva a uma economia maior no momento de pagar a conta. Tal aspecto é representado pela renda de até $\mathrm{R} \$ 510,00$, pelos itens 'Fecha o chuveiro enquanto se ensaboa' $(M=4,57)$; 'Desliga aparelhos eletrônicos enquanto não está usando' $(M=4,23)$; 'Espera os alimentos esfriarem para guardar na geladeira' $(M=4,57)$; e 'Diminui sua utilização de água' $(M=3,95)$. Com essas informações, percebe-se uma relação direta entre essa análise cruzada em relação às discussões realizadas na parte descritiva deste artigo.

Por fim, realizando a análise de diferença de médias com relação à escolaridade, a partir da ANOVA, percebe-se aquela que pode ser considerada como a maior contribuição desta pesquisa, das respostas analisadas de forma cruzada com a escolaridade, mais da metade dos indicadores demonstram diferenças de média entre os respondentes, o que indica ser esse elemento muito importante para o alcance do consumo consciente na população. Como está apresentado na Tabela 5 (destacado em negrito), dos 40 indicadores utilizados na pesquisa, 23 indicadores possuem essa diferença. Segundo Gomes (2006), a educação representa base para qualquer atitude e no que se refere ao comportamento de consumo pode contribuir para uma consciência. Tal fato pode ser aqui identificado, estando em consonância com o que Silva e Gómez (2010) indicam em sua discussão sobre consumo consciente.

Como já destacado ao longo de toda análise e de acordo com as informações expostas na Tabela 5 , entende-se que a relação entre educação e mudança contribui positivamente para a construção de um novo contexto, facilitando assim a continuidade do consumo. Dentre os indicadores que demonstram essa diferença de média para os grupos de escolaridade, pode-se destacar àqueles relacionados diretamente com a geração e gestão dos resíduos, bem como os critérios de compra utilizados. Isso sugere que a partir de informações e níveis de educação a compreensão de impacto torna-se modificado para parte dos respondentes, principalmente porque tais indicadores necessitam de um maior envolvimento com a mudança.

Essa ideia apresenta-se refletida nas variáveis 'Mobiliza-se para incentivar empresas a prevenir ou corrigir danos sobre o meio ambiente' $(M C=2,53 ; \mathrm{Mi}=2,79)$; 'Pratica e incentiva o consumo que apoie a inclusão e preservação' $(\mathrm{MC}=3,33 ; \mathrm{Mi}=3,50)$; e 'Costuma deixar de comprar produtos como punição' (MC=3,45; $\mathrm{Mi}=3,39)$, a partir dos níveis educacionais superiores - completo e incompleto, respectivamente. Esse perfil apresenta-se constante em outros indicadores analisados, o que sugere que mesmo com poucos respondentes nesse nível àquele que possuem relação com o nível superior demonstram mais consciência. Com isso, a sensação de pertencimento e potencial de mudança se mostra mais ressaltada e contribui para uma nova visão. A partir das considerações e análises, percebe-se que dentre os respondentes existe um direcionamento para práticas de consumo consciente, as quais, em determinados aspectos, sofrem influência da renda e da escolaridade e levam ao entendimento de que é possível o alcance do consumo sustentável, à medida que além 
Indicadores de consumo consciente: uma avaliação do recifense sob a ótica do consumo sustentável

das ações individuais a interação com outros atores (governos e empresas, por exemplo) leva a construção de uma rede de ações voltadas ao bem coletivo e direcionadas para práticas mais sociais.

\begin{tabular}{|c|c|c|c|c|}
\hline Critérios & Indicadores de Consumo Consciente & $\begin{array}{l}\text { Sig. } \\
\text { Levene }\end{array}$ & $\mathbf{F}$ & $\begin{array}{l}\text { Sig. } \\
\text { (ANOVA) }\end{array}$ \\
\hline \multirow{14}{*}{$\begin{array}{l}\text { Hábitos de } \\
\text { poupança }\end{array}$} & Como melhor se descreve seus gastos e hábitos de poupança & 0,000 & 1,299 & 0,241 \\
\hline & Evita deixar lâmpadas acesas em ambientes desocupados & 0,000 & 1,113 & 0,352 \\
\hline & Fecha a torneira enquanto escova os dentes & 0,003 & 1,793 & 0,076 \\
\hline & Fecha o chuveiro enquanto se ensaboa & 0,009 & 3,344 & 0,001 \\
\hline & Desliga aparelhos eletrônicos quando não está usando & 0,000 & 7,798 & 0,000 \\
\hline & Costuma planejar as compras de alimentos & 0,000 & 4,613 & 0,000 \\
\hline & Costuma pedir nota fiscal quando faz compras & 0,000 & 1,269 & 0,257 \\
\hline & Costuma planejar compra de roupas & 0,000 & 1,446 & 0,174 \\
\hline & Costuma utilizar o verso de folhas de papel já utilizadas & 0,000 & 6,052 & 0,000 \\
\hline & Espera os alimentos esfriarem antes de guardar na geladeira & 0,000 & 4,079 & 0,000 \\
\hline & Utiliza eletrodomésticos com rótulos de eficiência energética & 0,000 & 3,109 & 0,002 \\
\hline & Utiliza energia renovável & 0,000 & 2,675 & 0,007 \\
\hline & Diminui sua utilização de água & 0,021 & 3,779 & 0,000 \\
\hline & Não liga o ar condicionado diariamente para poupar energia & 0,176 & 0,805 & 0,598 \\
\hline \multirow{10}{*}{$\begin{array}{l}\text { Moradia e } \\
\text { Transporte }\end{array}$} & Quantas pessoas vivem na casa; & 0,000 & 0,429 & 0,904 \\
\hline & Quantos quartos existem na casa & 0,000 & 1,653 & 0,107 \\
\hline & $\begin{array}{l}\text { Realizou reforma ou pretende para possuir maior eficiência } \\
\text { doméstica }\end{array}$ & 0,000 & 0,909 & 0,508 \\
\hline & Leva em conta a proximidade e a facilidade de acesso & 0,001 & 2,743 & 0,006 \\
\hline & Dirige veículos motorizados (carro popular, mini van, caminhão) & 0,000 & 4,877 & 0,000 \\
\hline & Dirige sozinho um carro ou caminhão & 0,000 & 6,250 & 0,000 \\
\hline & Utiliza transporte público & 0,000 & 5,733 & 0,000 \\
\hline & Viaja de avião & 0,000 & 13,168 & 0,000 \\
\hline & Anda a pé ou de bicicleta & 0,383 & 2,502 & 0,011 \\
\hline & Possui fogão, água morna, ar condicionado & 0,000 & 16,703 & 0,978 \\
\hline \multirow{6}{*}{$\begin{array}{l}\text { Consumo de } \\
\text { bens } \\
\text { (sustentáveis } \\
\text { ou } \\
\text { orgânicos) e } \\
\text { alimentos }\end{array}$} & Consome alimentos importados &, 724 & 7,023 & 0,078 \\
\hline & Consome galinha & 0,019 & 0,483 & 0,868 \\
\hline & Consome carne & 0,000 & 1,609 & 0,119 \\
\hline & Consome frutos do mar & 0,367 & 1,736 & 0,087 \\
\hline & Consome frutas e vegetais & 0,005 & 4,195 & 0,000 \\
\hline & Consome água de garrafa & 0,002 & 1,351 & 0,215 \\
\hline \multirow{7}{*}{$\begin{array}{l}\text { Origem de } \\
\text { produtos, } \\
\text { publicidade } \\
\text { feita pelas } \\
\text { empresas, } \\
\text { critério de } \\
\text { compras }\end{array}$} & Consome alimentos cultivados na sua região & 0,000 & 3,911 & 0,000 \\
\hline & Consome alimentos que você plantou & 0,002 & 0,787 & 0,614 \\
\hline & Lê o rótulo atentamente antes de decidir a compra & 0,000 & 3,272 & 0,001 \\
\hline & $\begin{array}{l}\text { Procura passar ao maior número possível de pessoas as } \\
\text { informações que aprende sobre empresas e produtos }\end{array}$ & 0,000 & 1,497 & 0,155 \\
\hline & $\begin{array}{l}\text { Mobiliza-se para incentivar as empresas a prevenir ou corrigir os } \\
\text { danos ao meio ambiente causados por suas atividades }\end{array}$ & 0,031 & 2,46 & 0,013 \\
\hline & $\begin{array}{l}\text { Pratica e incentiva o consumo de produtos que apoiem ações de } \\
\text { inclusão social ou de proteção ao meio ambiente }\end{array}$ & 0,000 & 2,779 & 0,005 \\
\hline & $\begin{array}{l}\text { Costuma deixar de comprar produtos de empresas como } \\
\text { punição por terem feito algo prejudicial à sociedade ou ao meio } \\
\text { ambiente }\end{array}$ & 0,000 & 2,117 & 0,032 \\
\hline \multirow{3}{*}{$\begin{array}{l}\text { Geração e } \\
\text { gestão de } \\
\text { resíduos }\end{array}$} & $\begin{array}{l}\text { A família separa o lixo para reciclagem (lata, papel, vidro, PET, } \\
\text { garrafas). }\end{array}$ & 0,000 & 2,765 & 0,005 \\
\hline & $\begin{array}{l}\text { Preocupa-se em usar recursos de modo que não tragam } \\
\text { prejuízos para a sociedade e ao meio ambiente }\end{array}$ & 0,000 & 3,558 & 0,000 \\
\hline & $\begin{array}{l}\text { Apoia campanhas de outras ações que incentivem as pessoas } \\
\text { para a reciclagem dos materiais, redução do lixo e reutilização } \\
\text { dos produtos. }\end{array}$ & 0,001 & 1,996 & 0,045 \\
\hline
\end{tabular}

Tabela 5 - Teste de diferença de média com relação a escolaridade

\section{Considerações Finais}

Considerando que o consumo é apontado como umas das causas da insustentabilidade e que o seu crescimento é um processo que impulsiona as pessoas a comprarem mais e de forma indiscriminada, descartando o que possui com mais facilidade, é importante desenvolver mecanismos para que não haja uma forte relação entre a produção e o consumo, no sentido de uma reestruturação e na busca por alternativas positivas para as atuais práticas. Em função disso, à medida que foram articulados os indicadores do consumo consciente utilizados na pesquisa: Greendex, Ecological Footprint Method e Instituto Akatu, apesar de não assumir um caráter de obrigação social, os mesmos podem contribuir nesse sentido à medida que consegue representar as contribuições individuais. Com esses indicadores é possível uma visão ampla sobre os comportamentos e práticas quanto à busca pela sustentabilidade. 
Foram identificadas ao longo das análises que são muitas as práticas dos consumidores direcionadas ao consumo consciente, dentre as quais se destacam àquelas relacionadas com a economia de energia e água, que podem ter maior destaque pela grande necessidade que se tem desses recursos na vida cotidiana. Apesar desse entendimento, foi inferido que muito é feito pelo fator econômico e não por haver uma consciência em relação aos efeitos do seu consumo. Além disso, identificou-se que grande parte das respostas possuem diferenças de médias quanto às variáveis 'renda familiar' e 'escolaridade', o que indica que tais aspectos influenciam na efetivação do comportamento consciente. A partir das análises, o objetivo de pesquisa foi alcançado contribuindo assim com o avanço nas discussões sobre a temática.

Além disso, verifica-se que dentro do contexto do consumo sustentável, considerado como possível, os consumidores podem ser considerados contribuidores positivos a partir da prática de seu comportamento consciente. Assim, em relação ao consumo sustentável, devido à amplitude do seu conceito, o mesmo foi considerado como plano de fundo para as análises, ao analisar os comportamentos individuais e como esses percebem e/ou interagem com outros atores sociais como empresas e governos. Como a pesquisa fez parte de um projeto maior, outros trabalhos estão sendo desenvolvidos para buscar identificar a influência ou, ainda, a relação entre as diferentes tipologias de consumo, para que haja uma melhor apresentação das diferenças e uma melhor articulação teórica para futuras pesquisas.

Como limitação operacional toma-se a dificuldade na aplicação dos questionários, pois como a amostragem grande, divididas por Regiões Político-Administrativas, a aplicação dos questionários não foi rápida, e complicou-se em função da necessidade de deslocamento para essas regiões. Recomenda-se realizar a aplicação dos questionários em outras regiões do país para maior validação do mesmo, bem como para identificar quais são as principais diferenças entre as regiões existentes. Além disso, entende-se que os indicadores podem ser aplicados para com outras populações que não apenas regiões, como, por exemplo, estudantes, na busca por verificar as informações que estão sendo repassadas para os mesmos.

Assim, para melhor validade dos dados, sugere-se a necessidade de ponderação entre os critérios e indicadores considerados, por meio da atribuição de diferentes pesos, bem como a construção estatística a partir de validação nomológica (considerando que os dados levantados podem ser validados em campo) para alinhamento entre as variáveis, na construção de um conjunto de indicadores de consumo consciente que esteja mais bem adequado a diferentes contexto e situações. Portanto, sugere-se ser necessário um maior aprofundamento teórico com relação aos critérios e indicadores apresentados, bem como sua validação estatística a partir de uma visão operacional. Assim, com todas essas considerações, percebe-se que a pesquisa é contributiva para novos estudos sobre a temática, pelos resultados que foram identificados, devendo haver avançar no que se refere a renda e escolaridade, por exemplo. Além disso, buscar criar visões operacionais para o consumo sustentável, aproximando as visões de diferentes atores sociais, dentre os quais os consumidores pelo consumo consciente.

\section{Notas}

1- Agradecemos aos avaliadores por todas as recomendações que foram realizadas ao longo do processo de avaliação por meio do sistema double-blind review, já que os mesmos contribuíram direta e significativamente para uma melhor argumentação e articulação da proposta para o presente artigo científico.

\section{Referências}

Assadourian, E. (2010). Ascensão e queda das culturas de consumo. In: Worldwatch Institute. Estado do Mundo, 2010: estado do consumo e o consumo sustentável, Salvador: Uma Editora.

Cortez, A. T. C. \& Ortigoza, S. A. G. (2007). Consumo Sustentável: conflitos entre necessidades e desperdício. São Paulo: Editora UNESP.

De Toni, D., Mattia, A. A., Larentis, F. \& Silva, M. G. R. (2010). Um estudo sobre a configuração da imagem do conceito de consumo consciente. Anais do V Encontro Nacional da Associação Nacional de Pós-Graduação e Pesquisa em Ambiente e Sociedade. Florianópolis.

Dobson, A. (2003). Citizenship and the Environment. Oxford: Oxford University Press.

Eddine, S. C., Vettorazzi, K. M. \& Freitas, V. P. (2008). Consumo e Sustentabilidade: Desafios para uma nova atitude ecológica. Anais do XVII Congresso Nacional de Pesquisa e Pós-Graduação em Direito. Brasília, DF, Brasil.

Fabi, M. J. S., Lourenço, C. D. S. \& Silva, S. S. (2010). Consumo Consciente: a atitude do cliente perante o comportamento sócio-ambiental empresarial, Anais do IV Encontro de Marketing da Associação Nacional PósGraduação em Administração, Florianópolis, SC, Brasil.

Feital, J. C. C., Spers, E. E., Novaes Netto, A. F., Spers, V. R. E. \& Ponchio, M. C. (2008). O consumo consciente da água: um estudo do comportamento do usuário doméstico. Anais do /l/ Encontro de Marketing da Associação Nacional Pós-Graduação em Administração. Curitiba, PR, Brasil. 
Feitosa, M. J. S., Cândido, G. A. \& Firmo, L. A. (2010). Sistemas de indicadores de sustentabilidade: uma aplicação do ecological footprint method no município de Campina Grande (PB), Ambiência - Revista do setor de Ciências Agrárias e Ambientais, 6 (3).

Foladori, G. (2005). Sustentabilidad Alternativa. Uruguai: Coleccion Carbichui.

Gilg, A., Barr, S. \& Ford, N. (2005). Green consumption or sustainable lifestyle? Identifying the sustainable consumption, Futures, 37, pp. 481-504.

Gomes, D. V. (2006). Educação para o consumo ético e sustentável. Revista Eletrônica do Mestrado em Educação Ambiental, v.16.

Gómez, C. R. P., Parísio, D., Castillo, L. A. G. \& Santos, J. F. (2009). Ecological Footprint Method como ferramenta para avaliar o perfil do consume consciente, Revista Alcance, 16 (3), p. 321-338.

Hair Jr, J. F., Black, W. C., Babin, B. J., Anderson, R. E. \& Tatham, R. L. (2009). Análise Multivariada de Dados. (6 ed.). Porto Alegre: Bookman.

Instituto Akatu. (2001). O que é Consumo Consciente? Recuperado em Fevereiro, 2011, de <http://www.akatu.org.br/consumo_consciente/oque>.

Instituto Akatu. (2007). Como e por que os brasileiros praticam o consumo consciente? São Paulo: Instituto Akatu.

Instituto Brasileiro de Geografia e Estatística. (2009). Perfil da população recifense. Recuperado em Fevereiro, 2011, de <http://www.ibge.gov.br/home/>.

Jackson, T. (2004). Negotiating Sustainable Consumption: A review of the consumption debate and its policy implications, Energy \& Environment, 15 (6). p. 1027-1051.

Jackson, T. (2007). Sustainable Consumption. In: Atkinson, G., Dietz, S., Neumayer, E. (Ed.). Handbook of Sustainable Development. Edward Elgar Publishing.

Lenzen, M., Murray, J., Sack, F. \& Wiedmann, T. (2007). Shared producer and consumer responsibility: Theory and practice, Ecological Economics, p. 27-42.

Malhotra, N. (2006). Pesquisa de Marketing: uma orientação aplicada. 4. ed. Porto Alegre: Bookman.

Michaelis, L. (2000) Ethics of consumption. Oxford: Oxford Centre for the Environment, Ethics \& Society.

Michaelis, L. (2003). The role of business in sustainable consumption, journal of Cleaner Production, 11 (8), p. 915-921.

National Geographic. (2010a). Greendex. Recuperado em Novembro, 2011, de

<http://environment.nationalgeographic.com/environment/greendex/>.

National Geographic. (2010b) About the study. Recuperado em Novembro, 2011, de <http://environment.nationalgeographic.com/environment/greendex/about-the-study/>.

Panarotto, C. (2008). O meio ambiente e o consumo sustentável: alguns hábitos que podem fazer a diferença, Revista das relações de consumo, Caxias do Sul, RS, Brasil.

Pereira, A. (2004). Guia prático de utilização do SPSS: Análise de dados para Ciências Sociais e Psicologia. 5. Lisboa: Edições Silabo.

Portilho, M. F. F. (2005). Sustentabilidade Ambiental, consumo e cidadania. São Paulo: Cortez.

Ribeiro, J. A. \& Veiga, R. T. (2011). Proposição de uma escala de consumo sustentável, Revista de Administração da USP, $46(1)$, p.45-60.

Richardson, R. J., Peres, J. A. S., Wanderley, J. C. V, Correia, L. M. \& Peres, M. H. M. (2008). Pesquisa Social: métodos e técnicas. São Paulo: Atlas.

Sachs, I. (2007). Rumo à ecossocioeconomia: Teoria e prática do desenvolvimento. São Paulo: Cortez.

Santos, T. C., Leite, A. P. R., Tacconi, M. F. F. S. \& Alexandre, M. L. (2008). Movimento do Consumo Consciente: do Cidadão Consumidor ao Consumidor Cidadão? Anais do Encontro de Administração Pública e Governança EnAPG. Salvador, BA, Brasil.

Seyfang, G. (2006). Ecological citizenship and sustainable consumption: examining local organic food networks, Journal of Rural Studies, (22), p. 383-395.

Silva, M. E. (2011). A contribuição de práticas empresariais responsáveis para o consumo sustentável no varejo de supermercados: O caso Walmart Brasil. 137p. Dissertação (Mestrado em Administração) - Programa de PósGraduação em Administração (PROPAD). Universidade Federal de Pernambuco, Recife, PE, Brasil.

Silva, M. E. (2012). Consumo Sustentável: A Articulação de um constructo sob a perspectiva do desenvolvimento sustentável, Revista Eletrônica de Ciência Administrativa, 11 (2). 
Silva, M. E., Corrêa, A. P. M., Costa, A. C. V., Albuquerque, A. E. C. \& Almeida, J. A. J. (2012). Perfil de consumo consciente por meio de atitudes e comportamentos individuais: Um estudo com a população do Recife/PE, PMKT Ciência - Revista Brasileira de Pesquisa de Marketing, Opinião e Mídia, (10).

Silva, M. E. \& Gómez, C. R. P. (2010). Consumo Consciente: O papel contributivo da educação, Revista Reuna (Belo Horizonte), 15 (3), p.43-54.

Spaargaren, G. \& Oosterveer, P. (2010). Citizen-Consumers as Agents of Change in Globalizing Modernity: The Case of Sustainable Consumption, Sustainability, 2 (7), p.1887-1908.

VanBellen, H. M. (2005). Indicadores de Sustentabilidade: Uma análise comparativa. Rio de Janeiro: Editora FGV.

Vieira, D. M. (2010). O consumo socialmente irresponsável. Anais do IV Encontro de Marketing da Associação Nacional Pós-Graduação em Administração. Florianópolis, SC, Brasil.

Wackernagel, M. \& Rees, W. (1996). Our Ecological Footprint: reducing human impact on the earth. Canada: New Society Publishers.

World Commission on Environment and Development. (1987). Report Our common future. Genebra. Recuperado em Setembro, 2010, de <http://www.un-documents.net/wced-ocf.htm.>.

Wu, E. C., Cutright, K. M. \& Fitzsimons, G. J. (2011). How asking "Who Am I" affects what consumers buy: the influence of self-discovery on consumption, journal of Marketing Research, 48(2).

Young, W., Hwang, K., McDonald, S. \& Oates, C. J. (2010). Sustainable consumption: green consumer behavior when purchasing products, Sustainable Development, 18(1), p.20-31. 